Infirmary, for reviewing the lingular biopsies, and Miss E. McLean for secretarial assistance.

\section{REFERENCES}

Arnott, W. M. (1963). Brit. med. F., 2, 765.

Bannister, R. G. (1960). Lancet, 2, 329

Bishop, J. M., and Wade, O. L. (1963). Clin. Sci., 24, 391.
Fraser, K., and Kerr, I. F. (1961). Brit. med. Y., 2, 339.

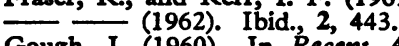
Gough, J. (1960). In Recent Advances in Pathology, 7th ed., p. 54,

Harris, P., and Heath, D. (1962). The Human Pulmonary Circulation. Livingstone, Edinburgh

Heath, D., and Best, P. V. (1958). F. Path. Bact., 76, 165.

and Edwards, J. E. (1.958). Circulation, 18, 533.

Lowther, C. P., and Turner, R. W. D. (1962). Brit. med. ₹., 1, 1027.

\title{
Prevention of Urinary Infection in Gynaecology
}

\author{
W. A. GILLESPIE,* M.A., M.D., F.R.C.P.I., D.P.H. ; G. G. LENNON,* M.B., CH.M., F.R.C.O.G., M.M.S.A. \\ K. B. LINTON,* B.SC., PH.D. ; N. SLADE,* M.B., CH.B., F.R.C.S.
}

Brit. med. F., 1964, 2, 423-425

Drainage of the bladder after gynaecological operations is most conveniently performed by indwelling catheter, but this method has recently come into disrepute because it nearly always gave rise to urinary infection. Infection can usually be avoided, however, by combining closed aseptic bladder drainage with measures to prevent bacteria from reaching the bladder via the space between the catheter and the urethral wall. After the removal of the indwelling catheter, the susceptibility of the bladder to infection may be temporarily increased, and special care must therefore be taken to avoid infection if intermittent catheterization subsequently proves necessary before the patient leaves hospital.

We have previously described how application of these principles reduced the post-operative infection rate (Linton and Gillespie, 1962). Having subsequently simplified the methods, we here describe them in more detail and report the results of treating a larger number of patients. We also report observations on the causative bacteria and on the aftereffects of infection.

\section{Method}

Immediately before the patient went to the theatre the urethra was lubricated and disinfected with about $1 \mathrm{ml}$. of $1 \%$ chlorhexidine (Hibitane) obstetric cream, instead of the special disinfectant jelly previously used (Gillespie et al., 1962). The cream was dispensed in urethral syringes ${ }^{1}$ in the hospital pharmacy and a separate syringe was kept for each patient.

The indwelling catheter for post-operative drainage consisted of a Foley catheter fitted tightly with a collar of plastic foam sponge (Fig. 1). Circular pads were cut and shaped in the central sterile supply department (C.S.S.D.) from a 1-in. $\left(2.5-\mathrm{cm}\right.$.) thick sheet of polyurethane plastic foam. ${ }^{2} \mathrm{~A}$ fine pair of forceps (Halsted's mosquito forceps) was thrust through the centre of the pad. The tip of the catheter was grasped and pulled back through the pad, which formed a very tight-fitting collar on the catheter.

This catheter was passed into the bladder before the patient left the operating-theatre (Fig. 2), and, after inflating the bulb, the pad was pushed along the catheter to rest firmly against the external urethral meatus and was well smeared with chlorhexidine obstetric cream. The catheter was thus

* United Bristol Hospitals and University of Bristol.

1 Plastic urethral syringes can be obtained from Messrs. Flexile Metal Co. Ltd., Bessemer Drive, Stevenage, Herts. Polyurethane plastic foam can be obtained from Messrs. Ranwal Ltd.,
Craddock Road, Skimpot Industrial Estate, Luton, Bedfordshire. prevented from moving in the urethra and a disinfectant barrier was maintained at the urethral orifice. The bladder was then disinfected by the method of Paterson et al. (1960), in which $2 \mathrm{oz}$. ( $57 \mathrm{ml}$.) of 1 in 5,000 aqueous solution of chlorhexidine digluconate was instilled into the bladder. The solution was usually run in by gravity from the barrel of a

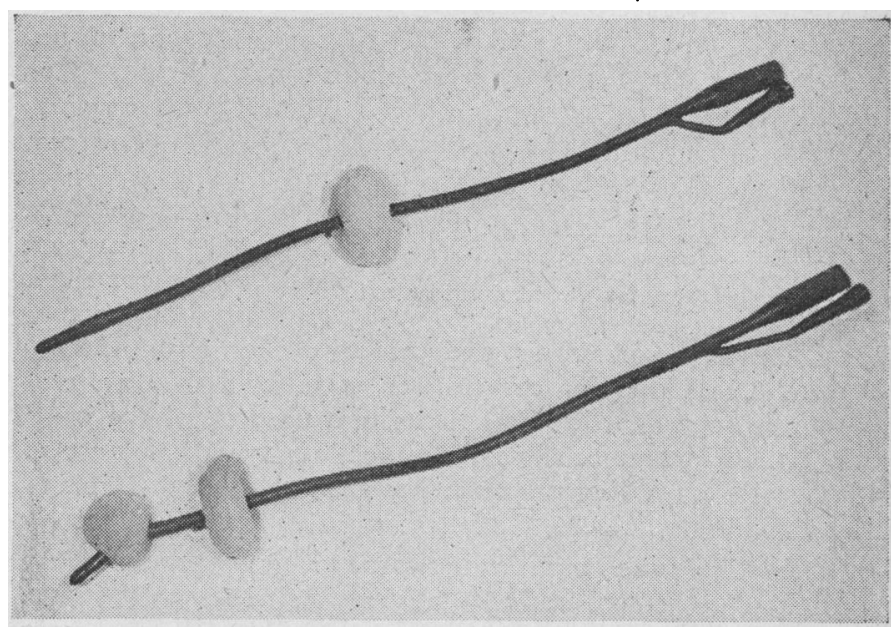

FIG. 1.-Foley catheters with pads of plastic sponge. (The balloon of the lower catheter is shown inflated, with the pad in approximately its final position.)

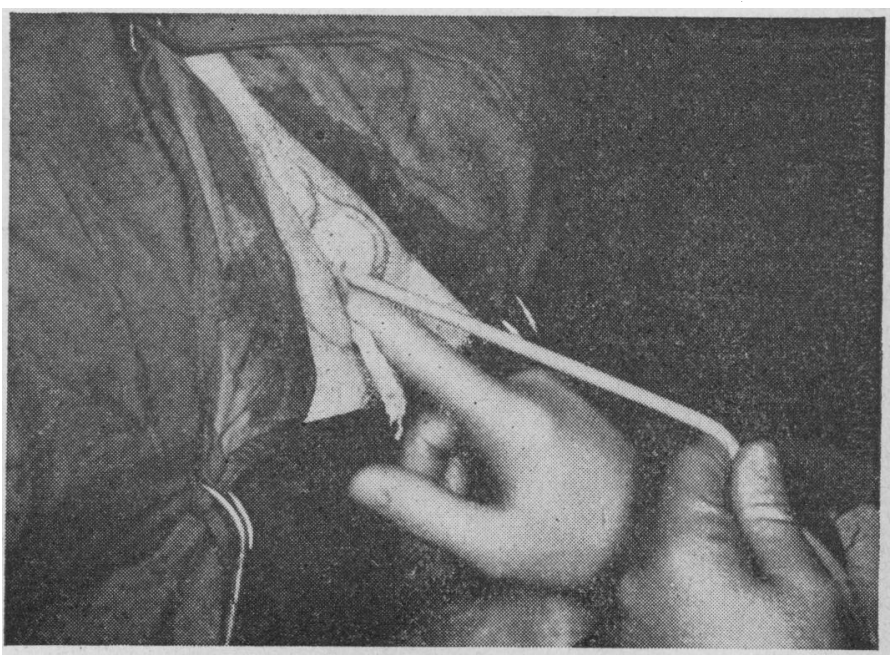

FIG. 2.-Sponge pad being pressed against urethral orifice, with tension on catheter. 
sterile polythene syringe attached to the end of the catheter. If the fluid did not run in freely, gentle pressure was exerted by the piston. The catheter was then closed with a sterile spigot.

In the ward the spigot was removed and the catheter was attached aseptically to a sterile rubber tube leading to a sterile closed-drainage apparatus. This consisted of a 2-litre bottle with handles to facilitate carrying (United Glass Bottle Co.). The bottles were assembled and disinfected in the C.S.S.D. by pouring in $100 \mathrm{ml}$. of liq. formaldehyde B.P.C. and inserting a sterile rubber bung fitted with two short glass tubes (Fig. 3). One tube ended in a sterile cotton-wool air filter,

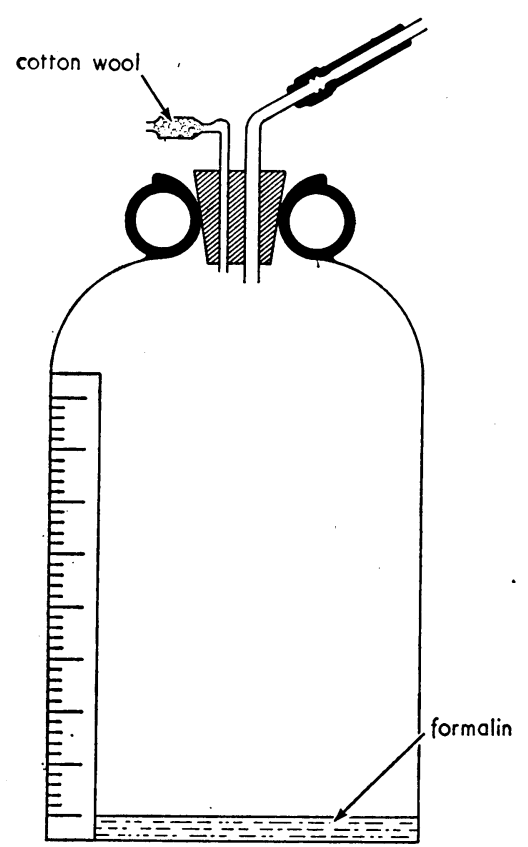

FIG. 3.-Apparatus for closed drainage and the other, protected before use by a glass cap, was for attachment to the drainage-tube. The bottle was allowed to stand for 24 hours before use to allow the formalin vapour to disinfect it.

Closed drainage was maintained for at least four days, during which the plastic foam pad was moistened twice daily with chlorhexidine obstetric cream. The patient could sit out of bed or walk about. The bottle was easy to carry and there was no risk of siphoning formalin into the bladder. When the bottle was changed the lower end of the tube was pinched to exclude air, and care was taken to avoid contamination. Urine for culture was withdrawn into a sterile syringe through a needle passed through the wall of the lower end of the drainage-tube after disinfecting it with tincture of iodine. By occluding the tube for a short time, 1-2 ml. of urine could be obtained. This was sufficient for culture.

Removal of the indwelling catheter was preceded by instillation of chlorhexidine solution, as described above. Subsequently if catheterization for residual urine was required, the same methods were used to disinfect the urethra before, and the bladder after, the passage of a catheter.

Urine was examined microscopically and cultured daily by a quantitative technique; fresh mid-stream specimens were used when the patient was not being catheterized. Infection was diagnosed when pathogens numbered more than 100,000/ $\mathrm{ml}$. and was usually accompanied by pyuria.

\section{Results}

Between February 1962 and August 1963202 patients had gynaecological operations-similar to those described in a previous series (Gillespie et al., 1962)-followed by four to five days of indwelling catheterization. Most patients were also catheterized intermittently between one and five times after the indwelling catheters were removed. Twenty-two patients whose urine was already infected were omitted from the investigation and 25 others were omitted because they were given antibacterial drugs, usually for respiratory infections. Of the remaining 155 patients, 23 (15\%) developed infection of the urine (Table I). This result was not quite as good as in our previous smaller and most closely supervised series of patients, but it was much better than the infection rate of nearly $100 \%$ experienced with open drainage and no disinfectants. The results might have been further improved by ensuring that the methods were always used correctly. Retrospective investigation of some cases revealed 28 in which major errors of technique occurred and $12(43 \%)$ of these became infected. Common errors were disconnexion of the drainage-tube to obtain urine specimens and the re-use of undisinfected drainage bottles because of failure to supply enough apparatus to the wards. These errors occurred mainly when the ward sister was absent, and were mainly attributable to our failure to provide written instructions of the new procedure.

TABLE I.-Urinary Infection in Patients with Indwelling Catheters

\begin{tabular}{|c|c|c|}
\hline Treatment & Total Patients & Infections \\
\hline $\begin{array}{l}\text { Previous series : } \\
\quad \text { Open drainage } \\
\text { Closed drainage and disinfectants ... }\end{array}$ & $\begin{array}{l}34 \\
39\end{array}$ & $\begin{array}{c}33(97 \%) \\
3(8 \%)\end{array}$ \\
\hline 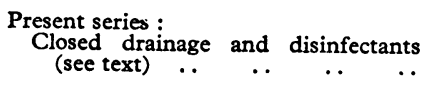 & 155 & $23(15 \%)$ \\
\hline
\end{tabular}

The avoidance of infection brought obvious clinical benefits. Patients had less pyrexia and discomfort and fewer needed antibiotics after operation.

Bacteriology of Infection in Relation to Method of Draining the Bladder.-Many of the infections which occurred with open drainage by indwelling catheter were caused by antibiotic-resistant bacteria, indicative of cross-infection by endemic ward strains which ascended from contaminated collecting-vessels. The bacteria included Proteus sp., Pseudomonas pyocyanea, Streptococcus faecalis, and Staphylococcus aureus, but the majority were lactose-fermenting coliform bacilli, among which klebsiellae outnumbered escherichiae. Klebsiellae have often been responsible for cross-infection among urological patients (Ørskov, 1952, 1954 ; Dutton and Ralston, 1957; Gillespie et al., 1960), and it has been suggested that they may develop drug-resistance more readily than E. coli (Talbot et al., 1957 ; Lattimer et al., 1959). The behaviour of coliform bacilli causing infection in our gynaecological patients was in line with these results. Unselected strains from different groups of patients were identified as recommended by Milner (1963). Strains from patients infected during open drainage, which promoted cross-infection, were mostly those of klebsiella. In contrast, klebsiellae were greatly outnumbered by $E$. coli and Citrobacter in circumstances where cross-infection was unlikely but the patient's own organisms, present in the urethra, might have reached the bladder-for example, by intermittent catheterization, during closed drainage by indwelling catheter, or when infection was acquired outside hospital (Table II). Most klebsiellae from open-drainage cases were resistant to sulphonamide and streptomycin, whereas the coliform bacilli from the other groups of patients were mostly sensitive.

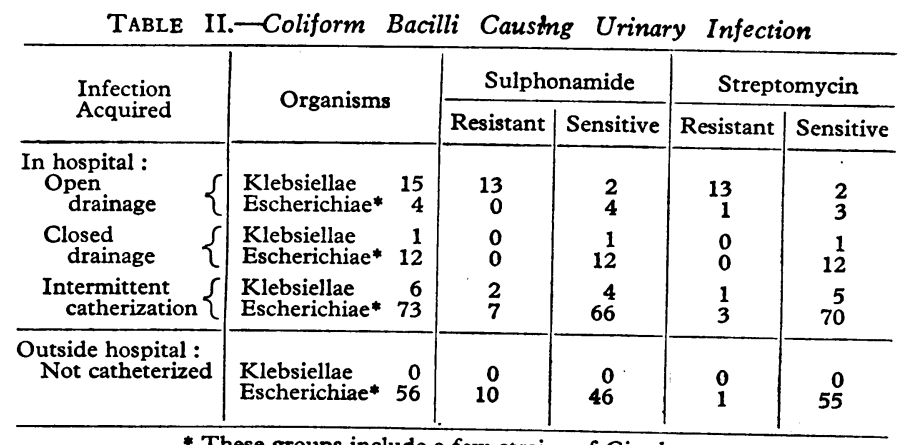


Consequences of Infection.-Kaye et al. (1962) and Cattell et al. (1963) found that catheter-induced infections rarely caused permanent damage of the urinary tract. Our findings were similar in a follow-up study of 85 patients who were treated with indwelling catheters before 1961. Thirty-two patients had normal urine when leaving hospital (infection having been avoided or having responded to treatment), and, of these, 31 were normal two years later and one was infected by a different organism from that which had caused infection in hospital. Of the 53 patients who left hospital with infected urine, only two were still infected by the same organism and one by a different strain. So far there has been no indication that hypertension, renal failure, radiological abnormality of the urinary tract, or abnormal urinary symptoms are commoner than in the other women of similar age.

\section{Discussion}

Post-operative drainage of the bladder is not always necessary, but, when it is, an indwelling catheter is more comfortable for patients and more convenient for nurses than frequent intermittent catheterization. The disadvantage of the indwelling catheter has been the infection which almost invariably followed its use with open drainage. Although the infections mostly clear up without serious harm there is always the danger that a few patients may suffer renal damage (though the proportion may be too small to detect in smallscale statistical studies). Furthermore, the post-operative comfort of the patients is often disturbed and many require treatment with antibacterial drugs. The indwelling catheter has consequently acquired a bad reputation, but this is undeserved, since infection is usually preventable. Our method of preventing it excludes bacteria from the two common routes of infection-that is, the lumen of the catheter and the space between the catheter and the urethral wall. Prophylactic antibiotics, which are generally agreed to be undesirable, are not required. Other workers have had similar success by combining closed drainage with antiseptics which destroy bacteria as soon as they enter the bladder (Williams et al., 1962 ; Martin and Bookrajian, 1962 ; Hannah, 1963).

The collecting-bottles used for closed drainage should be initially sterile and the accumulating urine should be kept sterile; otherwise a few organisms may enter the apparatus from time to time-for example, when a bottle is changed- and if allowed to multiply may cause infection. The apparatus should therefore contain a disinfectant and should be designed to prevent fluid from siphoning back into the bladder if the bottle is inadvertently raised above the level of that organfor example, when moving the patient on a trolley. So far we have found these conditions easier to fulfil with glass bottles than with plastic disposable vessels.

\section{Summary}

Urinary infection after post-operative catheterization in gynaecological patients was usually avoided by employing closed drainage with a modified Foley catheter to exclude bacteria from the lumen of the indwelling catheter and from the space between catheter and urethral wall. When intermittent catheterization was also necessary the urethra and bladder were disinfected with chlorhexidine.

Klebsiellae, often resistant to streptomycin and sulphonamide, outnumbered escherichiae in cross-infection occurring during open drainage. Escherichiae predominated in selfinfections and were usually sensitive to these drugs.

We thank Sister G. A. Phippen and her staff for their interest and excellent co-operation, which have made this work possible, and Mrs. Jean Mackenzie for help with the laboratory work.

\section{REFERENCES}

Cattell, W. R., Curwen, M. P., Shooter, R. A., and Williams, D. K. (1963). Brit. med. भ., 1, 923.

Dutton, A. A. C., and Ralston, M. (1957). Lancet, 1, 115.

Gillespie, W. A., Lennon, G. G., Linton, K. B., and Slade, N. (1962), Brit. med. $¥, 2,13$.

Linton, K. B., Miller, A., and Slade, N. (1960). F. clin. Path., 13, 187.

Hannah, W. J. (1963). Canad. med. Ass. F., 88, 803.

Kaye, M., de Vries, J., and MacFarlane, K. T. (1962). Ibid., 86, 9.

Lattimer, J. K., Seneca, H., Zinsser, H. H., and Troc, O. (1959). F. Amer. med. Ass., 170, 938.

Linton, K. B., and Gillespie, W. A. (1962). F. Obstet. Gynaec. Brit. Cwlth, 69, 845.

Martin, C. M., and Bookrajian, E. N. (1962). Arch. intern. Med., 110,

Milner, P. F. (1963). \%. clin. Path., 16, 39.

Ørskov, I. (1952). Acta path. microbiol. scand., Suppl. No. 93, p. 259. (1954). Ibid., 35, 194.

Paterson, M. L., Bart, W., and Macdonald, S. (1960). ¥. Obstet. Gynaec. Brit. Emp., 67, 394. Talbot, J. M., Cunliffe, A. C., and Gower, N. D. (1957). F. clin. Path.,

Williams, D. K., Garrod, L. P., and Waterworth, P. M. (1962). 9. Obstet. Gynaec. Brit. Cwlth, 69, 403. 